\title{
Erratum to: The validation of the Turkish version of Asthma Control Test
}

\author{
Mehmet Atilla Uysal • Dilsad Mungan - Arzu Yorgancioglu • \\ Fusun Yildiz • Metin Akgun - Bilun Gemicioglu • Haluk Turktas • \\ The Turkish Asthma Control Test (TACT) Study Group • \\ Gulcihan Ozkan · Insu Yilmaz • Mine Incioglu • Hasim Boyaci • \\ Sibel Atis · Aslihan Yalcin • Nazan Gulhan Bayram • \\ Figen Deveci · Didem Pulur • Eylem Selcan Ozgur • \\ Berna Dursun · Yilmaz Bulbul · Ebru Sulu • Veysel Yilmaz
}

Published online: 15 January 2013

(C) Springer Science+Business Media Dordrecht 2013

\section{Erratum to: Qual Life Res \\ DOI 10.1007/s11136-012-0309-1}

The individual members of the Turkish Asthma Control Test (TACT) Study Group should have been listed as full co-authors in the original publication. All authors are listed in this erratum.
The online version of the original article can be found under doi:10.1007/s11136-012-0309-1.

\section{A. Uysal ( $₫) \cdot$ G. Ozkan · V. Yilmaz}

Yedikule Hospital for Chest Diseases and Thoracic Surgery,

Training and Research Hospital, Istanbul, Turkey

e-mail: dratilla@yahoo.com

D. Mungan · I. Yilmaz

Department of Chest Diseases, Division of Allergy, Ankara

University, School of Medicine, Ankara, Turkey

\section{A. Yorgancioglu $\cdot$ M. Incioglu}

Department of Chest Diseases, Faculty of Medicine, Celal Bayar University, Manisa, Turkey

F. Yildiz $\cdot$ H. Boyaci

Department of Chest Diseases, Faculty of Medicine, Kocaeli

University, Kocaeli, Turkey

M. Akgun · D. Pulur

Department of Chest Diseases, Faculty of Medicine, Atatürk

University, Erzurum, Turkey

B. Gemicioglu

Department of Chest Diseases, Cerrahpasa Faculty of Medicine, Istanbul University, Istanbul, Turkey
H. Turktas

Department of Chest Diseases, Faculty of Medicine, Gazi University, Ankara, Turkey

S. Atis - E. S. Ozgur

Department of Chest Diseases, Faculty of Medicine, Mersin University, Mersin, Turkey

A. Yalcin

Department of Chest Diseases, Erzurum State Hospital, Erzurum, Turkey

N. G. Bayram

Department of Chest Diseases, Faculty of Medicine, Gaziantep University, Gaziantep, Turkey

F. Deveci

Department of Chest Diseases, Faculty of Medicine, Elazig University, Elazig, Turkey

B. Dursun

Department of Chest Diseases, Faculty of Medicine, Atatürk Hospital For Chest Diseases and Thoracic Surgery Training and Research Hospital, Ankara, Turkey 
Y. Bulbul

Department of Chest Diseases, Faculty of Medicine, Karadeniz

Technical University, Trabzon, Turkey

E. Sulu

Department of Chest Diseases, Sureyyapasa Hospital for Chest Diseases and Thoracic Surgery Training and Research Hospital, Istanbul, Turkey 